\title{
Intertextualidad y traducción: el caso de la traducción del manga Sailor $V$ en la década de los noventa
}

Intertextuality and translation: the case of the translation of the Sailor $V$ manga in the nineties

\author{
Salomón Doncel-Moriano Urbano \\ Doctorando en Lenguas, Textos y Contextos, Universidad de Granada, España \\ Investigador en el Graduate School of International Communication and Culture Studies, Universidad de Waseda, Japón \\ (salomondoncel@gmail.com)
}

Recibido el 16 de mayo de 2017; revisado el 3 de julio de 2017; aceptado el 7 de agosto de 2017; publicado el 1 de septiembre de 2017

RESUMEN: La intertextualidad en sus diferentes tipos constituye una propiedad de los textos que resulta útil a la hora de decodificar, enriquecer o modificar su significado intencional por parte del receptor. El manga Sailor $V$ muestra ejemplos claros de intertextualidad, así como distintos grados de mediación por parte del traductor en su versión al castellano, en la que se han empleado estrategias más o menos conservadoras con el objeto de mediar entre la autora y el lector, a fin de facilitar la comprensión de la miríada de mensajes que encierra la obra.

PALABRAS CLAVE: Manga, Traducción, Intertextualidad, Otakuología, Cultura Pop Japonesa.

\begin{abstract}
Intertextuality in its different types is a textual feature, which can be very useful to the recipient in order to decode, enrich or modify their intentional meaning. The manga Sailor $V$ portrays clear examples of intertextuality, as well as different degrees of mediation in its Spanish translation, where more or less conservative strategies have been applied with the aim of mediating between the author and the reader, for a better understanding of the myriad of messages contained in this masterpiece.
\end{abstract}

KEYWORDS: Manga, Translation, Intertextuality, Otakuology, Japanese Pop Culture. 


\section{Introducción}

El fenómeno intertextual ha sido estudiado en una amplia variedad de tipologías textuales. Sin embargo, no conocemos estudios que contemplen el grado de mediación por parte del traductor en la traslación interlingüística del género manga en los casos de intertextualidad. El presente artículo pretende analizar, grosso modo, distintos tipos de fenómenos intertextuales presentes en el manga Sailor $V$ y en su respectiva edición (y traducción al castellano), publicada por editorial Glénat (Takeuchi, 1999). Asimismo, en las líneas que siguen, se hará referencia a las estrategias traductológicas adoptadas por el traductor en la traslación de dichas intertextualidades, aludiendo a “intertextualidad contemporánea" e "intertextualidad clásica” en función de los textos de referencia que preceden a la obra que nos atañe.

Pese a la existencia de una reedición más contemporánea acompañada de una retraducción publicada por Editorial Norma (Takeuchi, 2012), esta no será abarcada en este breve análisis, permitiendo ser abordada, presumiblemente, en un futuro artículo. De igual modo, la literatura académica en lo tocante a análisis del discurso (Winter, 1994; Gutt, 1991; Hatim \& Mason, 1997; Hoey 1991; Beaugrande \& Dressler, 1981), datan en su mayoría de la década de los noventa, coincidiendo temporalmente con la edición original y la traducción objeto del presente estudio, pues no resultaría nomotético valorar la práctica traductológica del manga traducido en los noventa en base a formulaciones posteriores. En cualquier caso, estas serán útiles en un posible futuro análisis de la reedición de dicha obra.

\section{Intertextualidad: definición y tipos}

El término intertextualidad acuñado por la crítica literaria, filósofa y psicoanalista Julia Kristeva (1981), descrito como un "all pervasive textual phenomenon" (Hatim, 1997a, p. 29) y como a "precondition for the intellibility of texts" (Hatim \& Mason, 1997, p. 219), hace referencia al fenómeno en que un texto se refiere a otro mediante alusión, adaptación u otros medios de evocación de significado. Para recuperar el significado intencional (intended meaning ${ }_{1}$ ) de un texto en particular, los lectores deben reconocer y entender tales referencias intertextuales. La falta de percepción de estas ocasiona la comprensión parcial o incompleta del significado potencial del texto. Las implicaciones de este problema en el campo de la traducción son evidentes, puesto que la probabilidad de error en el

\footnotetext{
${ }^{1}$ El significado intencional se contrapone aquí al convencional, cuestionando la universalidad de las máximas de Grice al argumentar que el fenómeno de la implicatura sí es universal (Baker 1992, pp. 237-238).
} 
reconocimiento de referencias intertextuales entre lenguas y culturas diferentes es mayor que la que tiene lugar dentro de una misma lengua, debido a la falta de conocimiento sociocultural.

La intertextualidad puede operar "at any level of text organisation” (Hatim \& Mason, 1997, p. 18) ya sea fonológico, morfológico, sintáctico o semántico (Hatim, 1997b, p. 201), adquiriendo un significado cultural específico en una comunidad lingüística en particular en un momento concreto. Por ello, la intertextualidad puede incluir cualquier elemento que permita al lector identificar o derivar significado mediante los rasgos presentes de un texto con referencia a otros textos. El fenómeno intertextual no es casual, sino que suele estar motivado por la transmisión de significado.

Son muchos los autores que han expuesto su propia clasificación de intertextualidad en la literatura académica. Dentro del marco de los estudios sobre televisión, Fiske (1987, pp. 108-109) plantea la distinción entre la intertextualidad horizontal, la cual relaciona textos primarios que están ligados entre sí de forma más o menos explícita a través de los ejes de género, personajes o contenido; y la intertextualidad vertical, la cual establece una relación entre un texto primario y otros textos de diferente tipo que hacen alusión directa al mismo (textos secundarios y terciarios). Por su parte, Fairclough (1992, p. 283) divide las referencias intertextuales entre manifiestas (manifiest) y constitutivas (constitutive). La primera de ellas es la que suele marcarse mediante comillas u otros medios de citación, mientras que la segunda es más opaca y requiere del esfuerzo por parte del lector (o del mediador del acto comunicativo) de activar la fuente textual previa.

\section{Grado de mediación y estrategias de tratamiento del fenómeno intertextual}

De Beaugrande \& Dressler (1981) sostienen que el conocimiento intertextual se activa mediante un proceso que describen como "mediación", el cual hace referencia a la intervención de la subjetividad del comunicador, quien suele introducir sus propias creencias y conocimientos previos en la construcción de la situación comunicativa. Tanto en el proceso de creación como de traducción de textos, autor y traductor actúan como mediadores del acto comunicativo, sirviendo de puentes entre textos. Estos agentes mediadores podrán aplicar un "grado de mediación” variable, de modo que cuanto más tiempo y procesamiento sea necesario para relacionar el texto actual con los textos previos, más elevado será dicho grado de mediación. En el presente análisis, haré referencia únicamente a esta clasificación variable, puesto que podría decirse que las distinciones horizontal y manifiesta se solapan con un bajo grado de mediación, mientras que la vertical y la constitutiva generalmente requieren un mayor grado de mediación. 
Baker (1992, pp. 71-77 \& pp. 228-242) alude al concepto de implicatura2 (significado implícito que no figura explícitamente en el texto) y propone cinco estrategias de tratamiento del fenómeno intertextual a las cuales aludiré en mi análisis:

1. Traducción literal.

2. Sustitución cultural.

3. Elaboración y explicación por el traductor en el desarrollo del texto o mediante una nota al pie.

4. Translación mediante omisión.

5. Transliteración

\section{Estudio de caso: La intertextualidad de Sailor $V$}

El mangas Sailor $V$ de Naoko Takeuchi es un shôjo4 de tres volúmenes que vieron la luz por primera vez en la revista japonesa Run-Run de la editorial Kodansha en 1991. La obra relata la historia de Minako Aino, una adolescente de irreverente carácter y de cómo su tranquila vida cambia cuando un gato blanco llamado Artemis, aparece y le comunica que es Sailor V, una superheroína que debe proteger a la Tierra.

Sailor $V$ ofrece ejemplos de intertextualidad que podríamos clasificar atendiendo a la cronología de los textos a los que se refiere: intertextualidad contemporánea, cuando el referente anterior es un texto relativamente actual, e intertextualidad clásica en aquellos casos en que los textos previos pertenecen a la cultura grecolatina.

\footnotetext{
${ }^{2}$ Grice (1975) aclara la diferencia entre el significado que se manifiesta de forma explícita en una oración con lo que se sugiere o se manifiesta de forma indirecta en una proferencia de la misma cadena de palabras. La parte implícita o implicatura hace referencia al significado que está contenido en la unidad lingüística sin manifestarse de forma explícita. ${ }^{3}$ Manga: palabra japonesa que significa cómic y que actualmente se utiliza en español para referirse al cómic procedente de Japón.

${ }^{4}$ El shôjo, shojo o shoujo manga (少女漫画) es un tipo de cómic japonés destinado principalmente al público femenino adolescente. La palabra 少女 (shôjo) podría traducirse literalmente como “chica" o "muchacha”.
} 


\subsection{Intertextualidad contemporánea}

La obra original Sailor $V$ muestra varios ejemplos de referencia intertextual a textos contemporáneos. Ello se hace visible en el Acto 14 del tercer tomo (Takeuchi, 1997, pp.106-109). La escena muestra a la protagonista de la historia, Minako Aino, en un karaoke donde interpreta varias canciones fácilmente reconocibles por el lector japonés [1]. Estas canciones no requieren de comillas ni similares para ser fácilmente identificadas en el texto original y podríamos decir que su función es la de provocar la risa del lector y mostrar el lado más mundano y paródico del personaje en cuestión5. El siguiente cuadro refleja tales intertextualidades, citando en cada caso el fragmento que aparece en el manga original, el título de la canción y su intérprete, tanto en caracteres japoneses como en romaji6:

\begin{tabular}{|c|c|c|}
\hline FRAGMENTO & TÍTULO & INTÉRPRETE \\
\hline $\begin{array}{l}\text { あまぎ〜〜つ ご〜〜え〜〜つつつ } \\
\text { Amagigoe }\end{array}$ & $\begin{array}{l}\text { 天城越え } \\
\text { Amagi Goe }\end{array}$ & $\begin{array}{l}\text { 石川さゆり } \\
\text { Ishikawa Sayuri }\end{array}$ \\
\hline 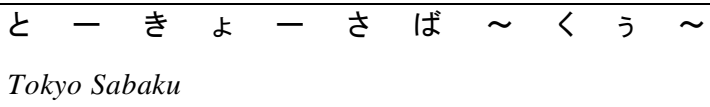 & $\begin{array}{l}\text { 東 京 砂 漠 } \\
\text { Tokyo Sabaku }\end{array}$ & $\begin{array}{l}\text { 内山田洋とクール・ファイブ } \\
\text { Uchiyamada Hiroshi y Kûru Faibu }\end{array}$ \\
\hline $\begin{array}{l}\text { 時 の 流 れ に 身 を ま か せ } \\
\text { Tokino nagarenii, Misumakaseee }\end{array}$ & $\begin{array}{l}\text { 時の流れに身をまかせ } \\
\text { Tokino nagareni miwo makase }\end{array}$ & $\begin{array}{l}\text { テレサ・テン } \\
\text { Teresa Ten }\end{array}$ \\
\hline 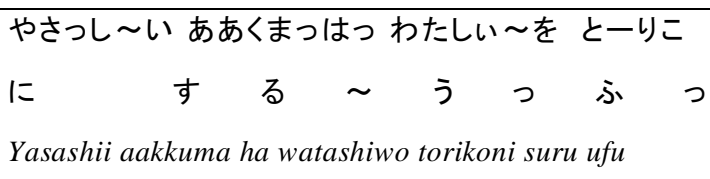 & $\begin{array}{l}\text { やさしい悪魔 } \\
\text { Yasashii akuma }\end{array}$ & $\begin{array}{l}\text { キャンディーズ } \\
\text { Kyandî-zu }\end{array}$ \\
\hline $\begin{array}{l}\text { あかい〜〜 スイイ } \sim \text { スピイ〜ッ } \\
\text { Akai Suiitopii }\end{array}$ & $\begin{array}{l}\text { 赤いスイートピー } \\
\text { Akai Suîtopî }\end{array}$ & $\begin{array}{l}\text { 松田聖子 } \\
\text { Matsuda Seiko }\end{array}$ \\
\hline $\begin{array}{l}\text { コオト〜の なかでわ ナニをいわれても ヘいき〜 } \\
\text { なのお 〜 アタックーッアタックーッ } \\
\text { Kôto no nakadewa naniwoiwaretemo heiki nano atakku } \\
\text { atakku }\end{array}$ & $\begin{array}{l}\text { アタック No.1 } \\
\text { Atakku nanbâ wan }\end{array}$ & $\begin{array}{l}\text { 大杉久美子 } \\
\text { Ôsugi Kumiko }\end{array}$ \\
\hline $\begin{array}{l}\text { トラトラトラ〜ッ こーいは いちーずー } \\
\text { Tora Tora Tora Koi ha ichizu }\end{array}$ & Tora tora tora & MAX \\
\hline
\end{tabular}

Cuadro 1 (Takeuchi 1997, vol. 3, pp. 106-109)

\footnotetext{
${ }^{5}$ Es de vital importancia saber que el alter ego de la protagonista, Minako Aino, es el de Sailor V, una mítica súper heroína. ${ }^{6}$ Caracteres romanos.
} 
En el cuadro superior figuran el fragmento, título e intérprete, de cada uno de los textos a los que se hace referencia en la mencionada escena del manga7. Las siete canciones enumeradas están, en cierto modo, arraigadas en el folclore japonés, de modo que cualquier lector medio nativo de la lengua origen las reconocería al instante. Basándonos en la clasificación variable (de Beaugrande \& Dressler, 1981) podríamos decir que al tratarse de canciones populares nos encontramos ante un tipo de referencia que refleja un alto grado de mediación por parte de la autora, puesto que el nivel en que esta aplica sus supuestos o creencias en el texto es muy elevado.
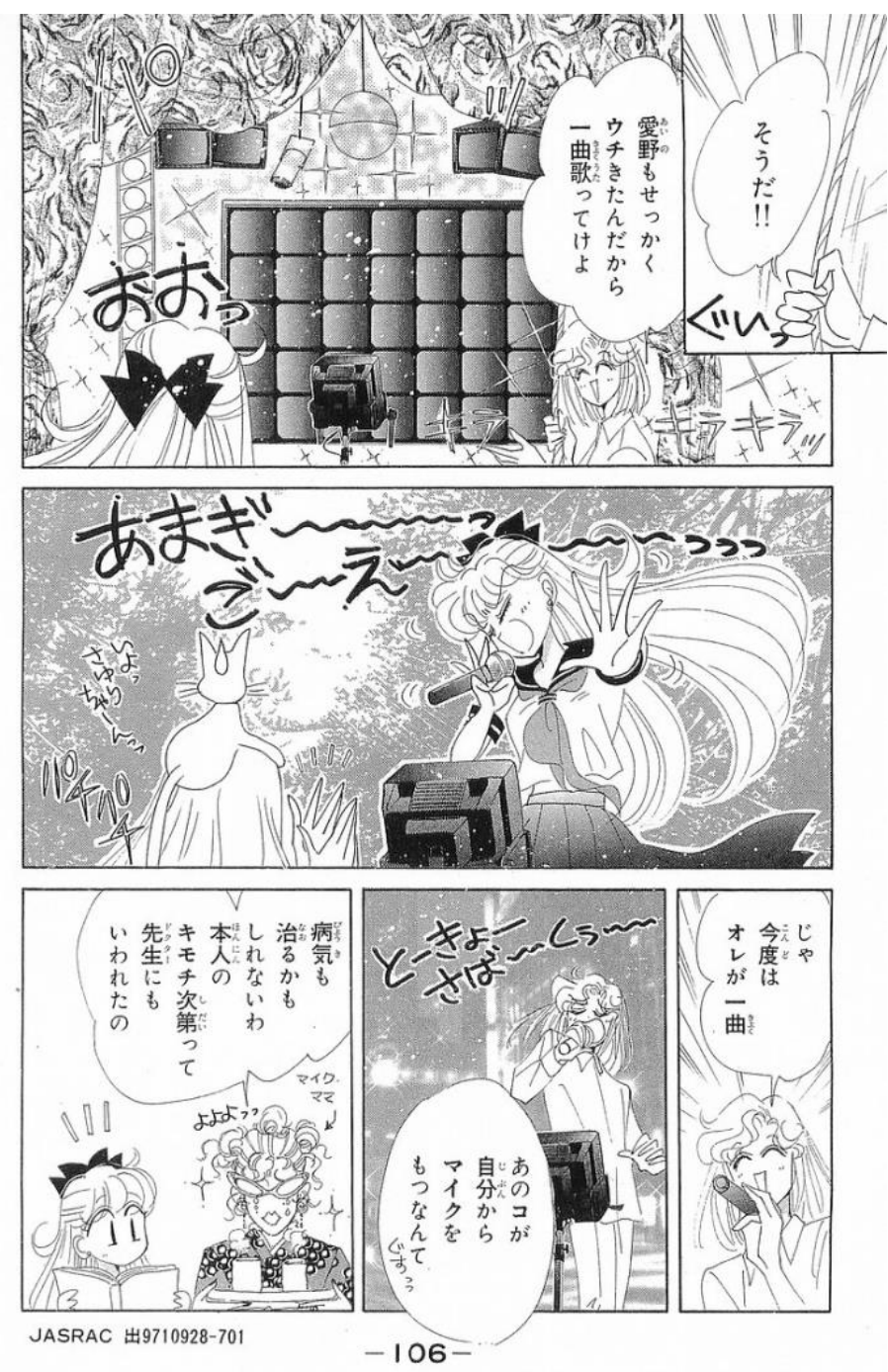

[Fig. 1] Takeuchi (1997) Vol. 3, p. 106. Escena del original japonés en que Minako Aino interpreta "Amagi goe" entre otros temas en un karaoke.

\footnotetext{
${ }^{7}$ No procede realizar una retraducción de las canciones mencionadas, puesto que ello no esclarecería ninguno de los aspectos sujetos a análisis en el presente artículo.
} 
El siguiente cuadro ilustra las intertextualidades que la edición española del manga publicado por Glénat ofrece en su traducción:

\begin{tabular}{|l|l|l|}
\hline FRAGMENTO & TÍTULO & INTÉRPRETE \\
\hline Desátame o apriétame más fuerte... & Desátame & Mónica Naranjo \\
\hline El talismán de tu piel me ha dicho... & El Talismán & Rosana \\
\hline Vivir así es morir de amor... & Vivir así es morir de amor & Camilo Sesto \\
\hline Libre, como el Sol cuando amanece yo soy liiibreee... & Libre & Nino Bravo \\
\hline $\begin{array}{l}\text { Bailar de lejos no es bailar, es como estar bailando } \\
\text { solo... }\end{array}$ & Bailar pegados & Sergio Dalma \\
\hline ¿iY cómo es él!? ¿ ¿En qué lugar se enamoró de tiiii!? & ¿Y cómo es él? & José Luis Perales \\
\hline Besos, ternura, qué derroche de amor... & Derroche & Ana Belén \\
\hline
\end{tabular}

Cuadro 2 (Takeuchi 1999, vol. 3, pp. 106-109)

En el cuadro 2 figuran el fragmento, título e intérprete, de cada uno de los textos a los que se hace referencia en la edición española del manga [2]. Las siete canciones enumeradas son fácilmente reconocibles por el lector español. Basándonos en la clasificación variable (de Beaugrande \& Dressler, 1981) podríamos decir que nos encontramos ante un tipo de referencia que implica, al igual que sucede en el TO (Texto Origen), un alto grado de mediación por parte del traductor, puesto que el nivel en que este aplica sus supuestos o creencias tanto en su comprensión del TO como en la recreación del TM (Texto Meta) es muy elevado. Cabe mencionar que no resulta imprescindible conocer la fuente exacta del texto original. Generalmente, basta con estar lo suficientemente familiarizado con el fragmento en particular (p.ej. “desátame o apriétame más fuerte”) para comprender su significado dentro del nuevo contexto; y en este caso, hacer una parodia del personaje y provocar la risa del lector.

Atendiendo a las estrategias de tratamiento que ofrece Baker, la traducción de Sailor $V$ en este caso ofrece una evidente sustitución cultural, puesto que el texto al que se hace referencia en él, la cultura origen es sustituido por otro cuya implicatura es la misma o similar en la cultura meta: canciones populares fácilmente reconocibles por el lector y cuyo significado implícito quedaría resumido explícitamente en la oración "la mística heroína es más mundana de lo que parece”. 

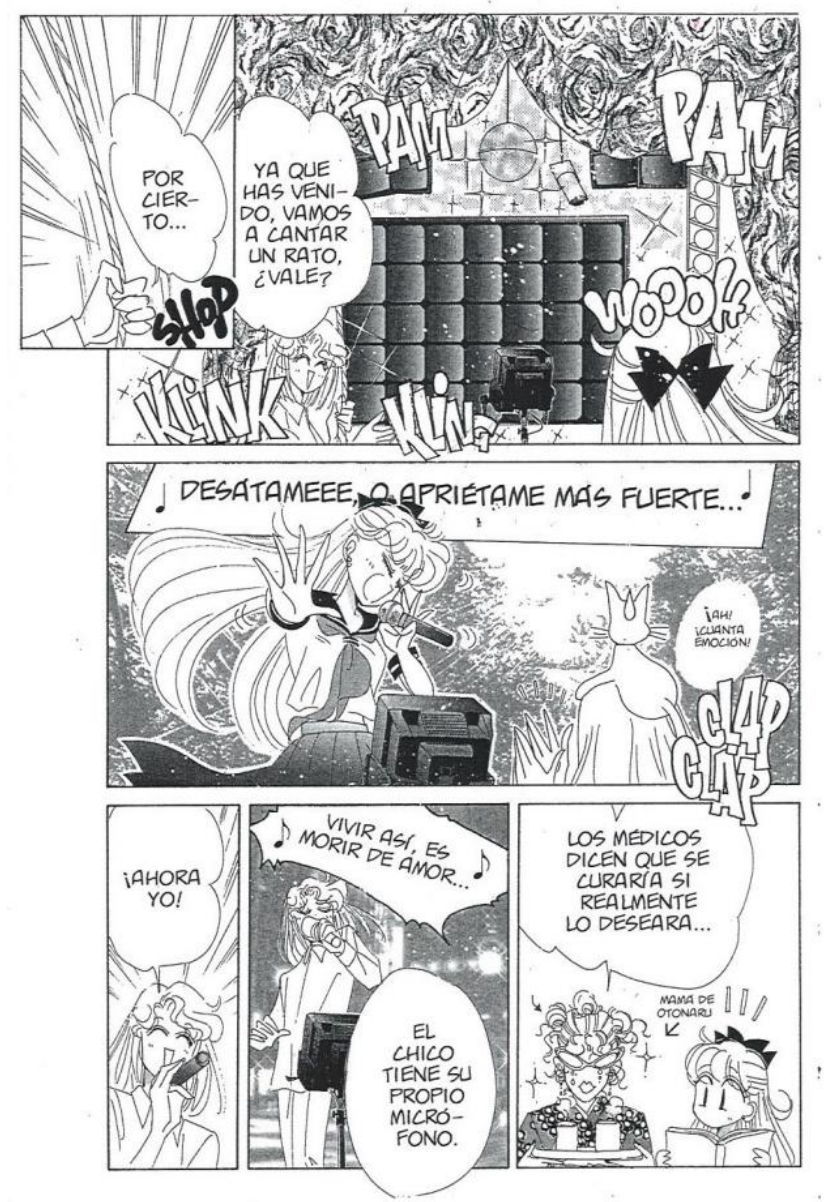

[Fig. 2] Takeuchi (1999) Vol. 3, p. 106. Traducción al castellano en que la autora y el traductor parodian a la protagonista en la escena de karaoke. Entre los temas adaptados se encuentran "Desátame” y "Vivir así es morir de amor".

\subsection{Intertextualidad clásica}

Mediante el desarrollo argumentativo del manga, Naoko Takeuchi deja entrever numerosas referencias intertextuales a textos clásicos de la Antigua Grecia. Con el fin de evitar un análisis demasiado extenso, nos detendremos solo en algunas de ellas.

La primera referencia intertextual de este tipo la encontramos en el nombre de la protagonista. Para comprender el modo en que se establece dicha referencia resulta esencial proceder a su análisis. El nombre "Minako Aino"s se puede dividir en cuatro partes diferenciadas: donde Ai significa "amor",

${ }^{8}$ 愛野美奈子 (Aino Minako) en japonés, donde el apellido precede al nombre. 
no es la partícula gramatical japonesa que denota posesión, Mina quiere decir "bella" y ko "niña"9 (Ferres 2001, pp. 60, 137, 207). Por lo tanto, el nombre completo podría traducirse al español como "la bella niña del amor".

Teniendo en cuenta que Afrodita era la diosa griega del amor y la belleza y que el alter egode Minako Aino, Sailor V [3], se refiere a sí misma como "la guerrera uniformada del amor y la justicia, Sailor Venus" 10 , podríamos asumir que el nombre en sí de la protagonista establece una intertextualidad con la griega Afrodita y su homóloga romana, la diosa Venus. Los siguientes fragmentos del manga original ilustran esta suposición:

\section{Fragmento 1:}

MINAKO: あのうかんでるのは?

ARTEMIS: マゼラン、マゼランキャンスル。金星アフロダイテ大陸上皇のき みのお汁。(Original)

MINAKO: ¿Qué es eso que flota?

ARTEMIS: Mazen, es el castillo de Mazen; la base espacial de Afrodita, tu castillo. (Retraducción)

(Takeuchi 1993, vol. 1, p. 24)

\section{Fragmento 2:}

ACE: これはヴィ--ナスの零。君が金星の海の泡から生まれたとき体か らこばれた零がほうぎょくになったもの。おばえてないのかい? プリンセスヴィ--ナス。(Original)

ACE: $\quad$ Es la gota de Venus, cuando naciste de la espuma del mar de Venus, una gota de agua resbaló de tu cuerpo y se transformó en joya. ¿No lo recuerdas, princesa Venus? (Retraducción)

(Takeuchi 1997, vol. 3, p. 150)

\footnotetext{
${ }^{9}$ Cabe destacar que el japonés posee tres métodos de escritura autóctonos diferentes: el hiragana, silabario con el que se escriben las palabras propias de la lengua, el katakana, silabario con el que se escriben los extranjerismos o préstamos de otras lenguas, y los kanji (o caracteres de origen chino). Estos últimos, además de denotar un nivel cultural más elevado que la escritura silábica, rigen el significado de las palabras. Por ejemplo, la sílaba en hiragana こ /ko/ significa "niña" cuando está representada por el kanji 子, pero también puede significar “aldea” (戸) o “arco" (弧).
}

10 愛と正義の戦士セーラービィナス (Takeuchi 1997: Vol 1, p. 44) 


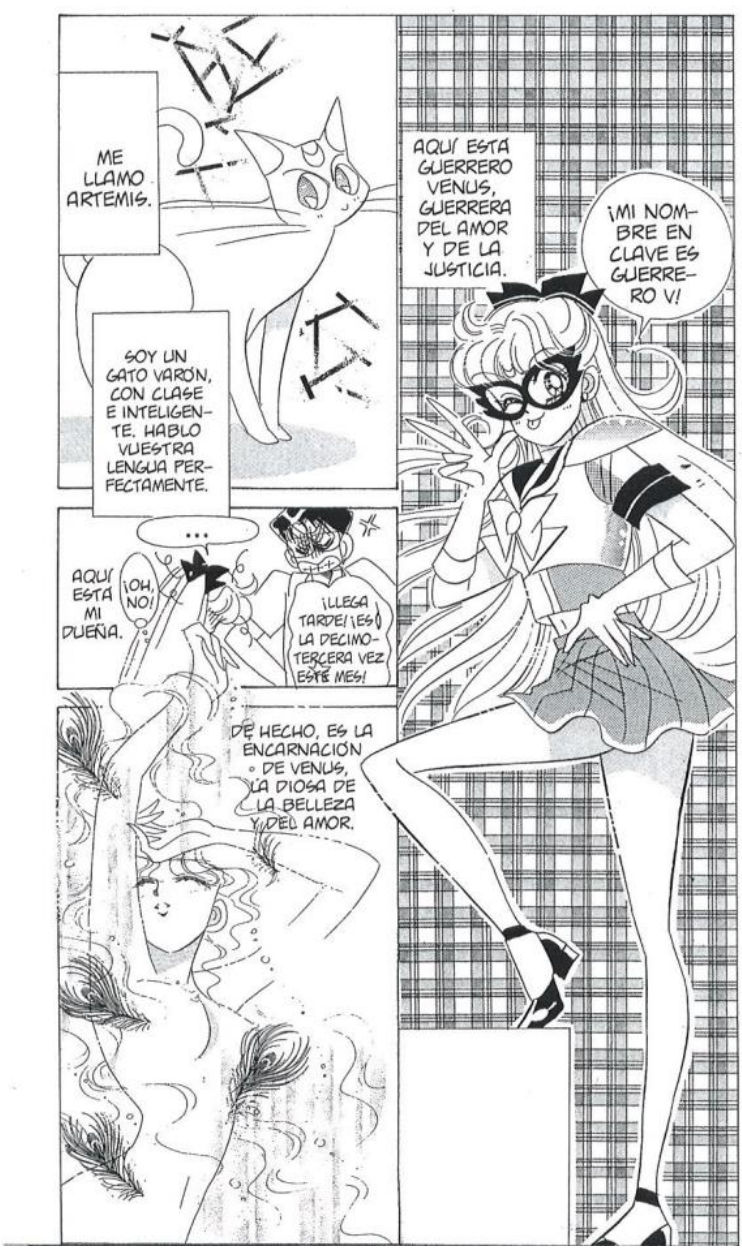

[Fig. 3] Takeuchi (1999) Vol. 1, p. 44. Sailor V se presenta ante su rival como "la guerrera del amor y la justicia", mientras que Artemis se refiere a ella como "la encarnación de Venus, la diosa de la belleza y del amor" estableciendo paralelismos con la diosa griega Afrodita y su homóloga romana, Venus.

Observando estos breves fragmentos, la suposición previa que surgía del análisis onomástico del personaje se confirma. Sailor $V$ establece una intertextualidad con la Teogonía de Hesíodo de la que se dice data de entre los siglos VII y VIII a. C y narra el origen del cosmos y el linaje de los dioses de la mitología griega [4]. El siguiente fragmento en castellano del texto clásico griego confirma esta teoría:

A su alrededor surgía del miembro inmortal una blanca espuma, y en medio de ella nació una doncella. [...] Salió del mar la augusta y bella diosa, [...] Afrodita [...] la llaman los dioses y hombres, porque nació en medio de la espuma. [...] La acompañó Eros y la siguió el bello Hímero al principio cuando nació, y luego en su marcha hacia la tribu de los dioses. Y estas atribuciones posee desde el 
comienzo y ha recibido como lote entre los hombres y dioses inmortales: las intimidades con doncellas, las sonrisas, los engaños, el dulce placer, el amor y la dulzura. (Hesíodo, 1978, versos 188-206) ${ }^{11}$.

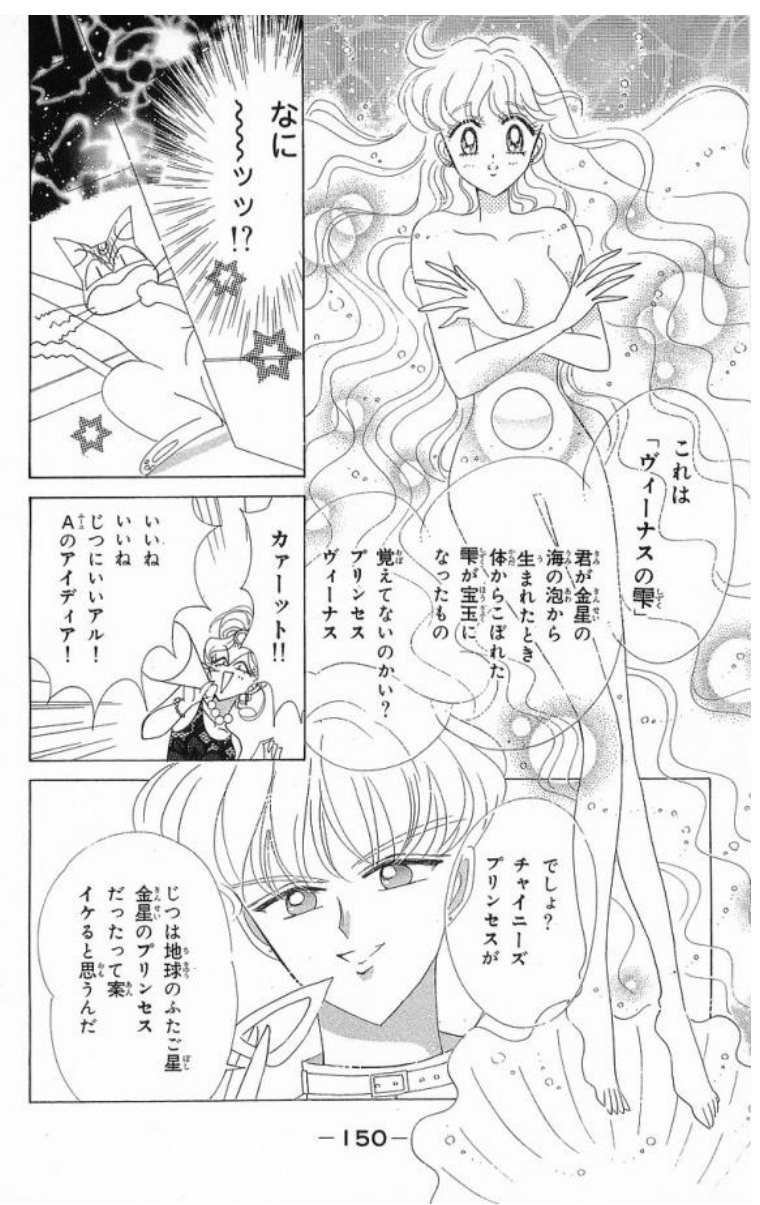

[Fig. 4] Takeuchi (1997) Vol. 3, p. 150. Viñeta original japonesa donde el gato Artemis narra el nacimiento de Venus.

Ante la patente intertextualidad que Sailor $V$ establece con la obra de Hesíodo, resulta de vital importancia observar cómo esta se trasladó al español [5]. En primer lugar, cabe destacar que la protagonista fue rebautizada como "Carola Aino". Si bien el significado del nombre original resulta desconocido para el lector español, la traslación mediante la omisión de la referencia intertextual supone la pérdida parcial del significado que poseía el TO. De origen alemán, "Carola" es una de las variantes de "Carla" y significa "mujer libre poseedora de bienes raíces" (G.M.Z. 2000, p. 51), no coincidiendo con el significado del nombre japonés. Aunque el apellido "Aino" se ha mantenido, el grado de mediación por parte del traductor es muy bajo, pues este no ha aportado sus suposiciones o creencias al texto en suficiente medida como para hacer clara dicha intertextualidad.

\footnotetext{
${ }^{11}$ Traducción de Aurelio Pérez Jiménez y Alfonso Martínez Diez.
} 
De acuerdo a la clasificación de Baker (1992), la estrategia que ha seguido el traductor es la combinación de la translación mediante omisión del nombre ("Carola", donde se pierde el significado y la implicatura del original) y la transliteración del apellido. La falta de presencia y claridad del significado original del nombre restringe parcialmente la comprensión potencial del texto. Una estrategia mixta que combinara la transliteración con la elaboración (mediante una nota por parte del traductor) hubiese ayudado a que no se perdiera el significado intencional del texto. Esta opción hubiese conservado la anticipación intertextual de la que goza el lector japonés, pues la nota habría paliado la falta de conocimiento lingüístico del receptor españolı.

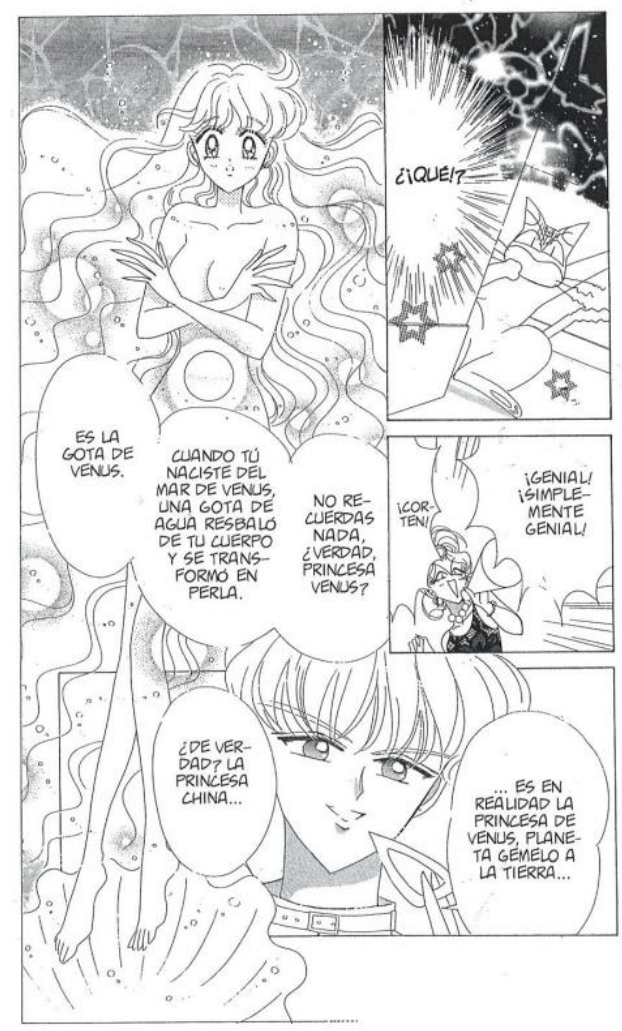

[Fig. 5] Takeuchi (1999) Vol. 3, p. 150. Viñeta adaptada donde, a través de la narración del gato Artemis, Takeuchi establece una evidente intertextualidad con la obra Teogonía de Hesíodo.

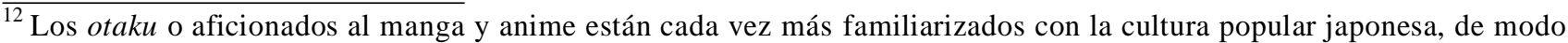
que, como consumidores de estos géneros, suelen exigir traducciones donde se conserven al máximo los rasgos culturales de las ediciones originales. Es por ello, principalmente, que en las ediciones actuales predomina la aplicación de la estrategia mixta en la que se opta por la transliteración y una breve explicación de su significado mediante notas de traducción (Doncel-Moriano, 2009, pp. 9-10).
} 
En cuanto a los breves fragmentos citados, la edición de Glénat ofreció las siguientes traducciones:

MINAKO: ¿Y aquello que flota abajo?

ARTEMIS: Es Magellan, el castillo de Mazeran. Es la base espacial de Afrodita. Es tu castillo.

(Takeuchi 1999, vol. 1, 24)

ACE: $\quad$ Es la gota de Venus. Cuando tú naciste del mar de Venus, una gota de agua resbaló de tu cuerpo y se transformó en perla. No recuerdas nada, ¿verdad, princesa Venus?

(Takeuchi 1999, vol. 3, 150)

Dejando al margen los evidentes errores de traducción y la incoherencia en la transliteración de nombres propios (p. ej. "Magellan” y “Mazeran”), estos fragmentos muestran que el traductor ha optado por una estrategia literal, que afortunadamente, ha dado buen resultado dentro del contexto del TM. No obstante, la elisión de la palabra "espuma" en la traducción, implica la pérdida de uno de los marcadores intertextuales más evidentes del fragmento.

Atendiendo a la clasificación variable (de Beaugrande \& Dressler, 1981), nos encontramos ante un tipo de referencia que, aunque efectiva, ha supuesto un bajo grado de mediación por parte del traductor, puesto que este ha recurrido a la translación literal, hecho que se refleja en la elisión de la palabra "espuma", la cual se habría mantenido si el traductor hubiese sido consciente de su importancia. No obstante, la proximidad cultural entre Grecia y España dota al lector español de conocimientos más amplios sobre mitología griega. Posiblemente, este posea información privilegiada sobre Afrodita y su nacimiento respecto al lector japonés y por lo tanto sea capaz de inferir el significado intencional del texto sin dificultades. En cualquier caso, ello no justifica la omisión arbitraria de información por parte del traductor.

\section{Conclusiones}

Tal y como se desprende de este artículo, la intertextualidad es un fenómeno crucial para el procesamiento de los textos entre lenguas. Uno de los problemas más complejos a los que se enfrenta el traductor es cómo verter estas referencias en el texto, la lengua y la cultura meta, consiguiendo que 
el significado implícito que evoca tal intertextualidad sea, cuanto menos, accesible para el lector. Frecuentemente, el proceso requerirá la creatividad del traductor, como es el caso de las canciones mencionadas en el primer apartado de este análisis, mientras que, en otros, una traducción literal bastará para mantener dicha referencia sin ocasionar pérdidas semánticas, como hubiese resultado en el extracto que hace alusión al nacimiento de Afrodita. Este planteamiento abre el debate de la ética profesional y la consideración de hasta qué punto el traductor debe mediar con el fin de mantener dichas intertextualidades; sobre si este debe mantener el significado más convencional del texto o si, por el contrario, su labor yace en el acercamiento al lector el significado intencional que este encierra.

Asimismo, pese a su brevedad, el presente estudio pone de manifiesto la necesidad indagar en las estrategias traductológicas aplicadas al manga en sus comienzos en España, sirviendo como llamamiento al estudio de la evolución que esta ha podido experimentar hasta nuestros días en base a un sinfín de condicionantes no abarcados en este análisis, como pudieran ser los estudios de recepción de la audiencia consumidora de este tipo de géneros.

Por último, pero no por ello menos importante, el análisis intertextual y traductológico de la obra de Takeuchi apunta a la relevancia cultural del manga, dentro y fuera de las fronteras de su país natal. En definitiva, el manga resulta un rico e interesante objeto de estudio dadas sus peculiaridades, la interdependencia entre texto e imagen, la existencia de su homólogo animado (anime) y los conceptos evocados a través de los mismos, llamando al despliegue de estudios más elaborados y transversales desde distintas perspectivas académicas, tales como la lingüística, el cine, los estudios culturales, de género, la historia y la iconografía, entre otros.

\section{Referencias bibliográficas}

BAKER, M. (1992). In Other Words: A Coursebook on Translation. Routledge: Londres.

DE BEAUGRANDE, Robert Alain. y DRESSLER, Wolfgang (1981). Introduction to Text Linguistics. Longman: Londres. 
DONCEL-MORIANO URBANO, Salomón (2009), "Prefacio del traductor", en NAVOK, Jay y RUDRANATH, Sushil (aut.), Guerreras de leyenda: el reflejo de Japón en Sailor Moon, pp. 9-10, Ellago Ediciones: Pontevedra.

FAIRCLOUGH, Norman (1992). Discourse and Social Change. Polity Press: Cambridge.

FERRES SERRANO, Juan José (2001). Gunkan: diccionario de kanjis japoneses, pp. 60, 137, 207, Hiperión: Madrid.

FISKE, John (1989). Television Culture. Routledge: Londres \& Nueva York.

GRICE, Paul Herbert (1975-1989), "Logic and Conversation”, en GRICE, Paul Herbert, Studies in the Way of Words, pp. 22-40, Harvard University Press, Massachusetts.

G.M.Z. (2000), Diccionario de los nombres [en línea]. [Buenos Aires, Argentina]. Recuperado de:http://www.scribd.com/doc/448666/diccionario-de-los-nombres-propios-y-su-significadomasc-y-fem (Consultado: 01/05/2017).

GUTT, Ernst-August (1991). Translation and Relevance. Blackwell:Oxford.

HATIM, Basil (1997a), "Intertextual intrusions: towards a framework for harnessing the power of the absent text in translation", en SIMMS, Karl. (ed.), Translating Sensitive texts: Linguistic Aspects, Rodopi: Amsterdam.

HATIM, Basil (1997b). Communication Across Cultures: Translation Theory and Contrastive Text Linguistics. University of Exeter Press: Exeter.

HATIM, Basil y MASON, Ian (1990). Discourse and the Translator. Longman: Londres.

HATIM, Basil y MASON, Ian (1997). The Translator as Communicator. Routledge: Londres.

HESÍODO (1978). Teogonía. Gredos: Madrid. 
HOEY, Michael (1991). Patterns of Lexis in Text. Oxford University Press: Oxford

KRISTEVA, Julia (1981). Semiótica. Fundamentos: Madrid.

TAKEUCHI, Naoko (1993-1997). Sailor V (vols. 1-3). Kodansha: Tokio.

TAKEUCHI, Naoko (1999). Sailor V (vols. 1-3). Glénat: Barcelona.

TAKEUCHI, Naoko (2012). Sailor V (vols. 1-2). Norma: Barcelona.

WINTER, Eugene (1994), "Clause relations as information structure: two basic text structures in English”, en COULTHARD, Richard Malcolm (ed.), Advances in Written Text Analysis, cap. 4, pp. 46-68, Routledge: Londres. 